\title{
UROLOGICAL OPERATIONS FOR IMPROVEMENT OF BLADDER VOIDING IN PARAPLEGIC PATIENTS
}

\author{
By E. Elsaesser, M.D. and E. Stoephasius, M.D. \\ Urologische Klinik and Poliklinik, University of Munich, Germany, \\ and Berufsgenossenschaftiches Unfallkrankenhaus Murnau, Germany
}

OuR department for paraplegic patients was opened in January I 969 and comprises 60 beds. In the past $2 \frac{1}{2}$ years it has been in service, a total of 554 paraplegic patients, 466 male and 88 female, have received treatment. In 65 of these cases, i.e. I 2 per cent., we performed 84 urological operations on the bladder and urethra.

Unfortunately, many of our patients do not come to us for treatment until several days, weeks or even months after their accident. As a result of the indwelling catheterisation to which they have been subjected beforehand they are already suffering on arrival from severe urinal infections and urological complications. Others are committed to our care years after accident because of secondary urological complications.

In our urological treatment of paraplegics we are attempting like Guttmann (1947, I966), to avoid urinal infections by non-touch catheterisation and to achieve regulated vesical function by conservative means, namely by consistent long-term bladder training.

Furthermore, we are guided by the awareness that even minor obstructions to urinary outflow from the bladder that can normally be overcome by a healthy bladder cannot be overcome by a paraplegic and hence have to be removed.

If urological operations for removing obstructions or pathological changes in the urethra and bladder are to be discussed in order of urgency the removal of bladder stones must come first. Bladder stones were diagnosed already on arrival in thirteen cases. These severely impair the bladder function and render the urinal infection resistant to therapy. The removal of stones is thus the first prerequisite for effective bladder training and antibiotic treatment. Litholapaxy can therefore not be performed soon enough, especially since it does not involve any risk to the patient (Table I).

Nowadays we are only removing bladder stones by the transurethral method using the 'Urat-I'. This apparatus delivers electro-hydraulic impulses that disintegrate the stones into tiny particles up to the size of sand grains. These can then readily be drained from the bladder. The advantage of this method is that it avoids troublesome haemorrhaging of the mucous membrane of the bladder and curtails the operation.

As you can see, we had no misgivings in removing an almost plum-sized bladder stone already three months after an accident which left the female patient with a complete lesion at the level of T6. Shortly afterwards the first spontaneous micturition was observed in the patient. In keeping with the intensive bladder training the amount of residual urine dropped in the next two months to values below $100 \mathrm{ml}$, and six months later the urine culture was sterile.

In six cases litholapaxy alone was sufficient to achieve good bladder function; in five cases an additional obstruction in the bladder neck had to be resected. 


\section{TABLE I}

\begin{tabular}{|c|c|c|c|c|}
\hline & \multicolumn{4}{|c|}{$\begin{array}{c}\text { Effect of Litholapaxy } \\
\text { on bladder function } \\
\text { (13 Patients) }\end{array}$} \\
\hline \multirow{2}{*}{$\begin{array}{l}+1 \text { - good, sterile urine on } \\
\text { dischorge } \\
\text { good, RU } 100 \mathrm{ml} \\
\mathrm{O}=\text { improved. RU } 100.200 \mathrm{ml} \\
-=\text { not improved. }\end{array}$} & \multicolumn{4}{|c|}{ Operation corried out months offer accident } \\
\hline & $0-3$ & $4-6$ & $7-12$ & $13 \longleftrightarrow 13$ Yeors. \\
\hline TETRAPL. & & + & & \\
\hline UMNL & $+!$ & $\begin{array}{l}+! \\
\mathrm{O} \stackrel{\text { IUR Prost. }}{\mathrm{O}}+\stackrel{\text { BNR }}{\longrightarrow} \mathrm{O}\end{array}$ & $\begin{array}{l}+! \\
+\end{array}$ & - (Blodder Neopl.) \\
\hline LMNL & & $+!$ & & $\begin{array}{l}-\frac{\text { IUR Prost. }}{\text { TUR Prost. }}+\text { ! } \\
-\stackrel{\text { BNR }}{\longrightarrow}+\text { + } \\
+\end{array}$ \\
\hline
\end{tabular}

TABLE II

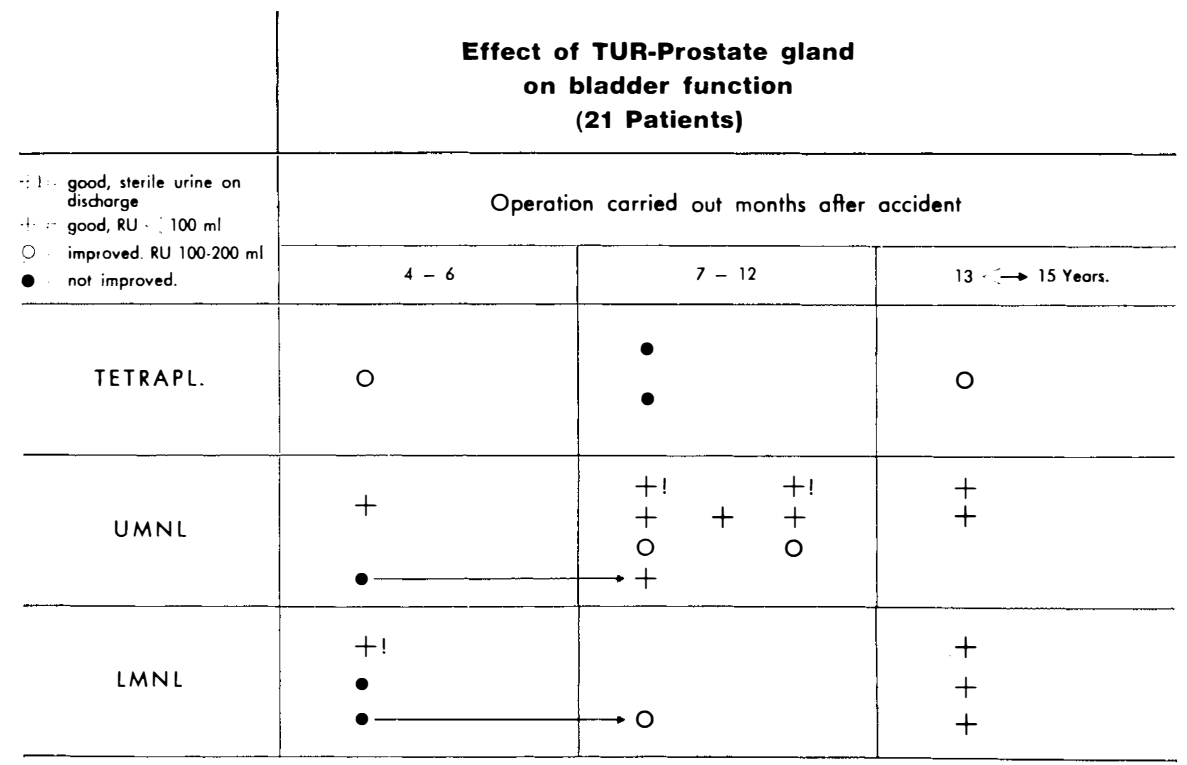

Good results were finally obtained in every case. The one exception was a 37-year-old male patient, a paraplegic for fifteen years, in whom we detected a squamous cell carcinoma of the bladder in addition to the stones. 
Just as urgently in need of operation as bladder stones are all anatomical obstructions to urinary outflow between the bladder neck and meatus externus urethrae (Table II).

Viewed purely in numerical terms, the main complaint is hypertrophy of the prostate, which we found in male patients above the age of 40-45 years a total of twenty-one times.

Transurethral resections of large adenoma, which without doubt must be regarded as an obstruction to bladder voiding, have been made very soon after recovery of the bladder reflexes, in order to afford bladder training greater prospects of success. As you can see, we did this twice with good results and once with moderate success; twice we had to perform post-resections of apical residues the results being good and satisfactory respectively.

In the second six-month period after accidents we have also made resections of small adenoma if bladder training alone has not proved successful.

The last group is composed of patients 13 months to I 5 years after the accident in which the renewed increase in residual urine indicates that these men have gradually reached the 'prostate age' and have now reacted, sooner than nonparaplegic patients suffering from the same complaint, with decompensation of bladder voiding.

In these cases the best chances of success were naturally afforded by T.U.R. of the prostate (fig. I).

Not to be overlooked are urethral strictures, which are not so rare in paraplegics because the regrettable application of long-term catheterisation continues. They occur most frequently in the meatus urethrae externus, where they can easily be removed by meatotomy. There were seven cases of this in our patients.

More serious are strictures in the penile urethra and peno-scrotal junction. The removal of these calls for two to three sessions of plastic surgery. They are frequently combined with urethral diverticula or urethral fistulae. Care should be taken in this operation to ensure not only that the fistula and diverticulum are removed, but also primarily that the stricture preventing urinary outflow is removed.

All of these operations therefore begin by slitting the strictured part of the urethra according to Johanson (1953). The subsequent closing of the hypospadic urethra is now generally performed by plastic surgery according to Denis Browne (I949) (fig. 2).

Unfortunately, the otherwise excellent method of Denis Browne involves a post-operative fistula rate of about 20 per cent. Recently, we have therefore been making frequent use of the method according to Cecil (1946, I952) and Micha Lowski (1963). This requires another session, but has the advantage that it is much less inclined to lead to recurrent post-operative fistulae because the tissue around the wound is free of tension.

The principle is as follows (figs. 3-6). In accordance with Denis Browne (I949) a strip of skin, the length of the hypospadias, is cut on the ventral side of the penis. It is then buried and the new urethra forms from it. The wound on the penis is not, however, covered with penile skin, the penis being stitched temporarily into the scrotum, which is slit along the raphe. One disadvantage is that a third operation is necessary eight weeks later to free the penis from the scrotum. This operation, however, is a minor one.

Whereas there is a clear indication, from the urological point of view, for all of the foregoing operations, the indications and value of bladder neck resection in 


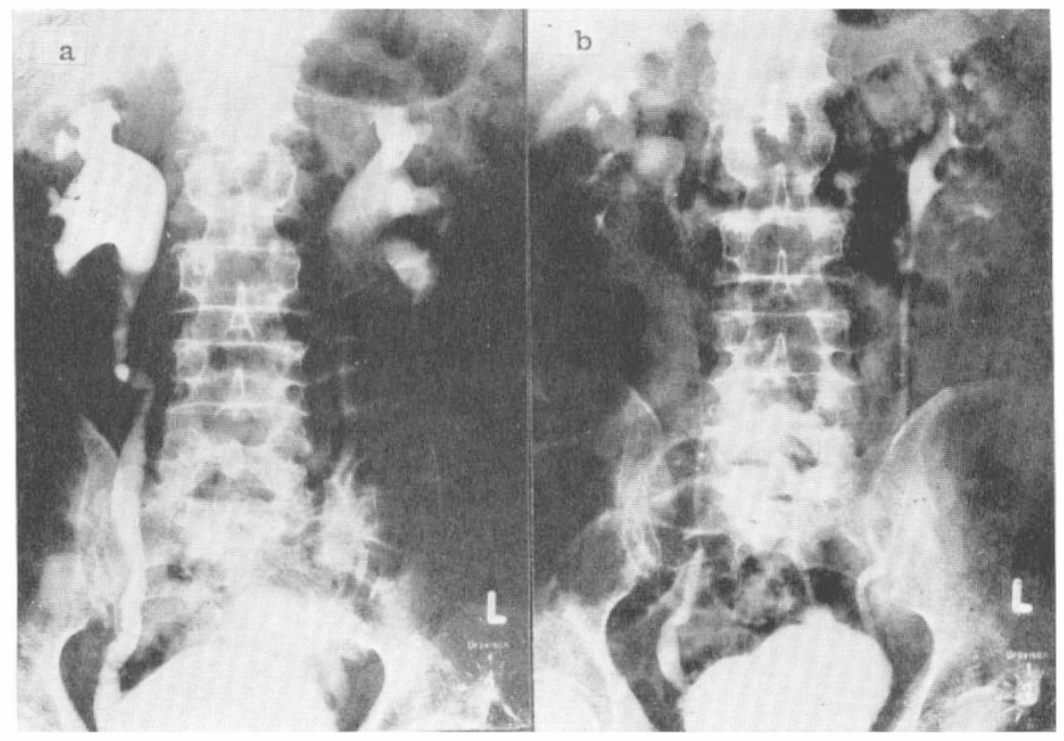

FIG. I

Fig. I.-(A) I.V.P. of a $64-$ year-old male patient with UMNL ( $\mathrm{T}_{4}$ ) suffering from enlarged prostate and bladder stone. Residual urine 300-500 ml., bilateral hydronephrosis. (B) I.V.P. of the same patient two months after Litholapaxy and T.U.R. of $28 \mathrm{~g}$. of prostate tissue. Residual urine below IOO $\mathrm{ml}$. Hydronephrosis improved.

Fig. 2.-(A) Urethraldiverticulum with urethral stricture (retrograde urethrocystogramm in a I9-year-old male paraplegic). (B) The same case after urethroplasty according to Johanson and D. Browne.

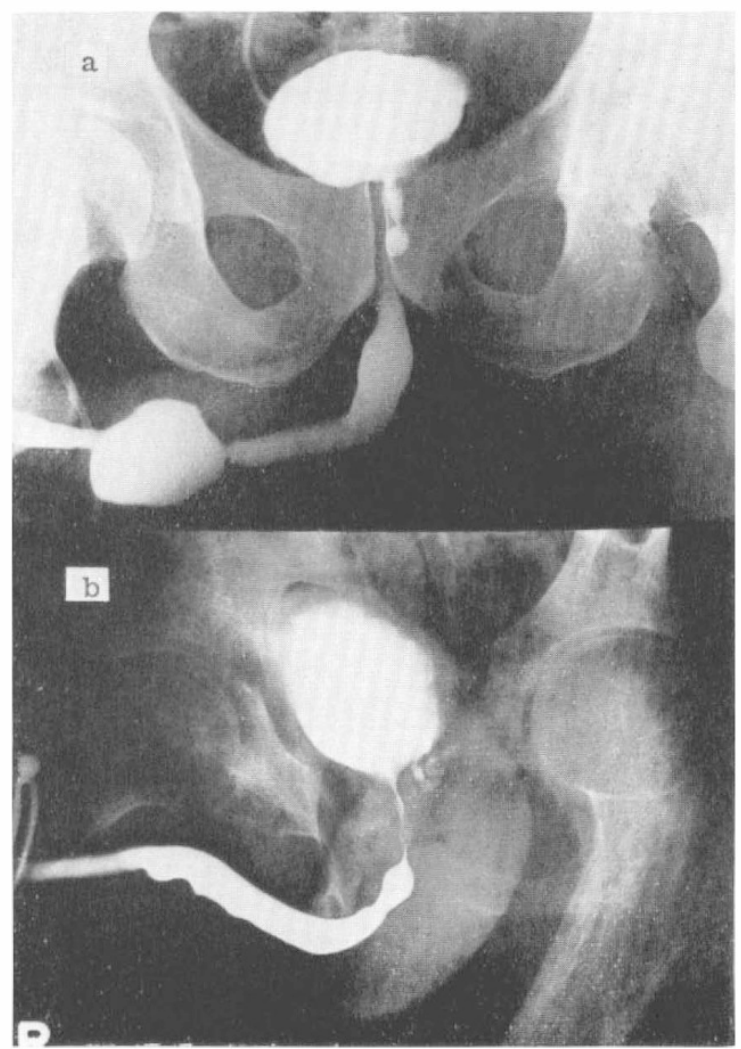

FIG. 2 


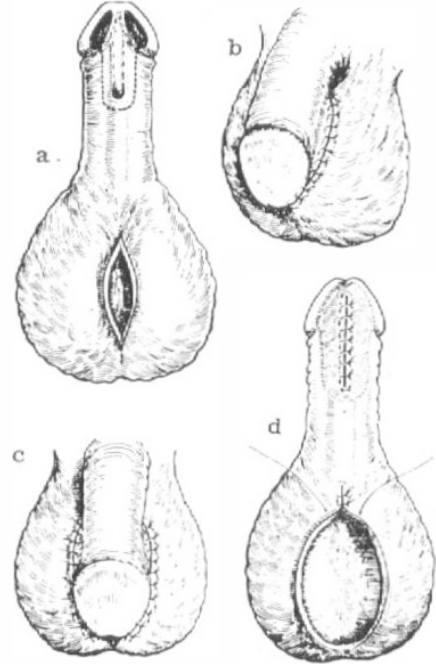

FIG. 3

Steps in operative procedure according to Cecil and Michalowski.

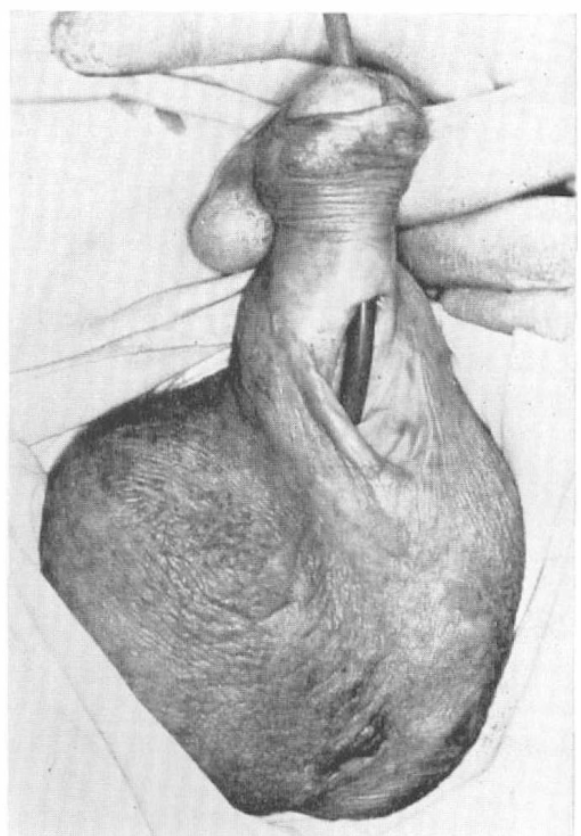

FIG. 4

Fig. 4.-Large urethral fistula in a 29 -year-old paraplegic after treatment with indwelling catheter.

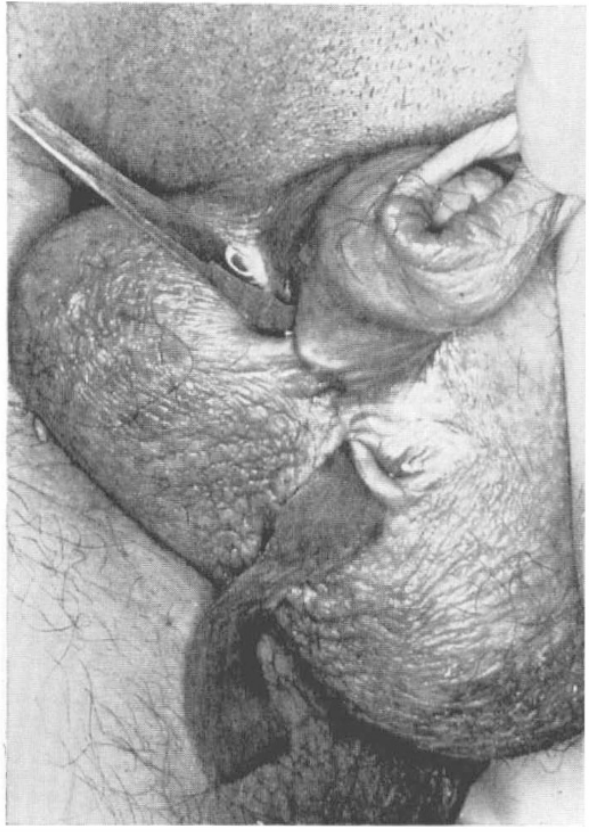

FIG. 5

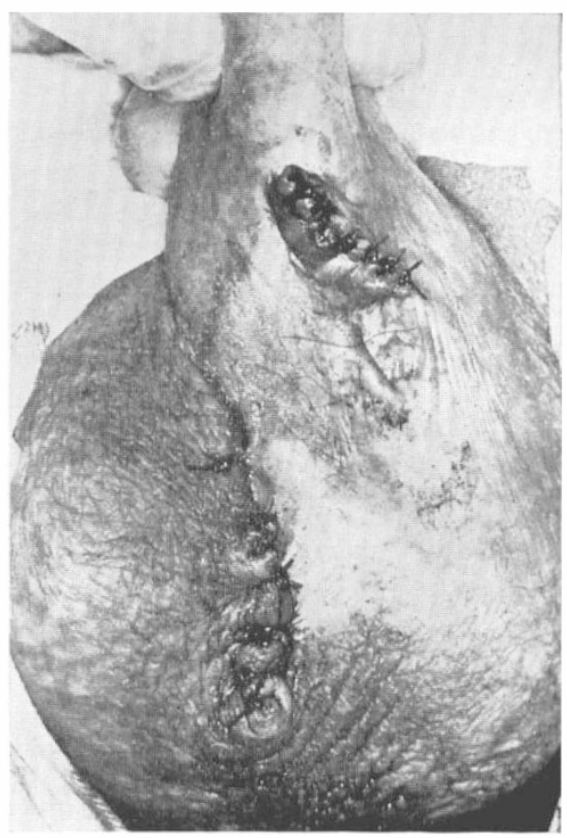

FIG. 6

Fig. 5.-Condition after urethroplasty according to Cecil and Michalowski: the penis is still partially embedded in the scrotum.

Fig. 6.-Final result after releasing the penis from the scrotum. 
paraplegics are contested. We were hesitant in deciding the indications for this operation. This is already evident from the fact that, of all our patients, we only treated 14 men and 9 women in this way.

Where bladder training failed in the long run we first applied cystoscopy on the patients concerned to determine whether any obstruction was present. Only when this revealed a prominent obstruction in the bladder neck did we remove this sclerotic ring by resection between 3 and 9 o'clock or, if necessary, full circle (Emmett, I945, I947). No resection was performed if the bladder neck showed no optically prominent obstruction.

\section{TABLE III}

\begin{tabular}{|c|c|c|c|c|}
\hline & \multicolumn{4}{|c|}{$\begin{array}{c}\text { Effect of bladder neck resection } \\
\text { in women on bladder function } \\
\text { ( } 9 \text { Patients) }\end{array}$} \\
\hline \multirow{2}{*}{ 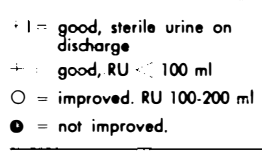 } & \multicolumn{4}{|c|}{ Operation carried out months affer accident } \\
\hline & $4-6$ & & & 13 \\
\hline \multicolumn{5}{|l|}{ TETRAPL. } \\
\hline UMNL & & & & \\
\hline LMNI. & & & $\begin{array}{c}+ \\
-+1 \\
\rightarrow+\end{array}$ & \\
\hline
\end{tabular}

Table III presents the results of bladder neck resections performed on the nine female patients. Seven were finally successful, one of these patients having to undergo post-resection twice, while in the other two cases the patients' condition could only be partially improved by the operation. It must be admitted that only in two cases did the improvement in bladder voiding occur directly after resection, and so there is certainly a causal relation here with the operation. In the other cases weeks to months passed before the successful results listed in the table were achieved. The question, therefore, in these seven cases is whether the improved bladder voiding is due to bladder neck resection or to the resumed bladder training.

Table IV presents the results of the same operation on the fourteen male patients. It can be seen that best results are obtained in the late cases. Here, too, the success of the operation very soon becomes evident and can thus be clearly ascribed to removal of the obstruction. In the cases of resection within the first year improvement did not occur till after 4-I 2 weeks as in the operations performed on the female patients.

A certain difference between early and late resections is also revealed by the 
results of histological examinations: in the first 12 months, tissue changes due to inflammation with strong oedema dominate, while in the late case sit is fibrosis and hyperplasia of the smooth musculature that mainly occur.

TABLE IV

\begin{tabular}{|c|c|c|c|}
\hline & \multicolumn{3}{|c|}{$\begin{array}{c}\text { Effect of bladder neck resection } \\
\text { in males on bladder function } \\
\text { (14 Patients) }\end{array}$} \\
\hline \multirow{2}{*}{$\begin{array}{l}\cdot I=\text { good, sterile urine on } \\
+ \text { discharge } \\
+ \text { good, RU }<100 \mathrm{ml} \\
O=\text { improved. RU } 100.200 \mathrm{ml} \\
-=\text { not improvod. }\end{array}$} & \multicolumn{3}{|c|}{ Operation carried out months affer accident } \\
\hline & $4-6$ & $7-12$ & $13 \rightarrow 13$ Years \\
\hline TETRAPL. & & $\stackrel{+}{\stackrel{O}{O+}} \stackrel{ }{\stackrel{+}{\longrightarrow} \text { Spht. }+}$ & + \\
\hline UMNL & + & 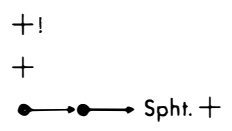 & $\begin{array}{l}+ \\
+\end{array}$ \\
\hline LMNL & + & & $\begin{array}{l}+! \\
+! \\
+\end{array}$ \\
\hline
\end{tabular}

Finally, the foregoing cases show that sclerosis in the bladder neck often constitutes a real obstruction to urinary outflow. For such patients, bladder neck resection affords a remedy. It is difficult, however, to select these cases properly by endoscopy.

In three cases, bladder neck resection failed completely: a tetraplegic patient died of urosepsis two months after the operation; in the other two cases a second bladder neck resection was of no avail. We therefore decided to perform for the first time a transurethral external sphincterotomy (Ross et al., I958, I963, I967; Smythe, I966; Currie et al., I970), which is recommended by British and American authors. For this purpose we used a right-angled fine tube electrode for coagulation. The cutting part is about $6 \mathrm{~mm}$. long. Like Currie et al. (1970), we make an incision at the level of the verumontanum at 3 and 9 o'clock and draw the instrument about $2 \mathrm{~cm}$. distal. Finally, we apply a Charr. I8-20 long-term catheter for 2-4 days.

These two patients on whom the operation was performed for the first time were capable of good, unobstructed bladder voiding immediately after the operation. Encouraged by this initial success, we have since operated on another six patients in this way.

The top line of Table $\mathrm{V}$ shows you the pressure values for the urethra and bladder: the retrograde urethral pressure shows a distinct post-operative decrease and is then almost always below the maximum cystometrographic pressures. The bottom line reveals the decline of residual urine that always sets in immediately after the operation. At this point it should be emphasised that pudendal nerve 
anaesthesia was applied repeatedly to all these patients but failed each time. There were no post-operative complications, the haemostasis by coagulation was always sufficient, and post-operative incontinence did not occur in any of the operated patients.

\section{TABLE V}

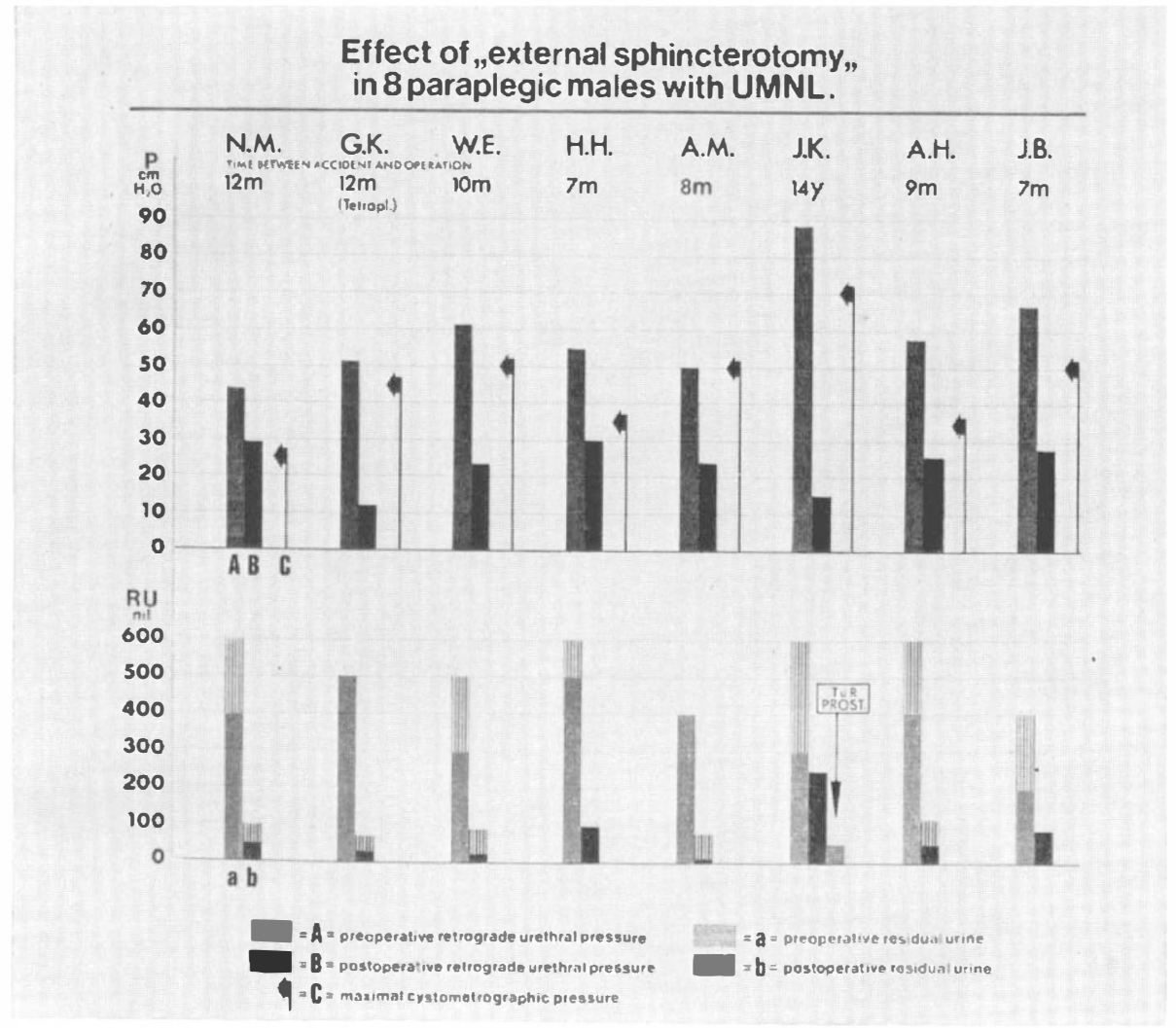

Only in a 52-year-old male patient, J. K., who had been a paraplegic for I4 years, was there an increase of residual urine after initial improvement. Here sphincterotomy was wrongly indicated. Success was only achieved after resection of the $8 \mathrm{~g}$. prostate gland. This case clearly reveals that T.U.R. of the prostate and external sphincterotomy have their special spheres of indication (fig. 7).

As can be seen from the publications (Ross et al., 1958, 1963, 1967; Smyth, 1966; Currie et al., 1970) and our small number of cases, sphincterotomy has been so successful that its application is always justified after the failure of bladder training if urological examination does not show any other obstruction and the manometry values show promise of success. From the urological standpoint, the only misgiving is that the operational wound in the urethra may lead to subsequent stricture of the urethra. So far there have been no reports of late after-effects in this connection. Only Ross et al. (1958, 1963, 1967) state in 1963 that a supra- 
pubic deviation was later necessary in 3 of 40 patients who underwent a sphincterotomy.

We should be glad if this question could be treated in the following discussion and wish to thank you for your attention.

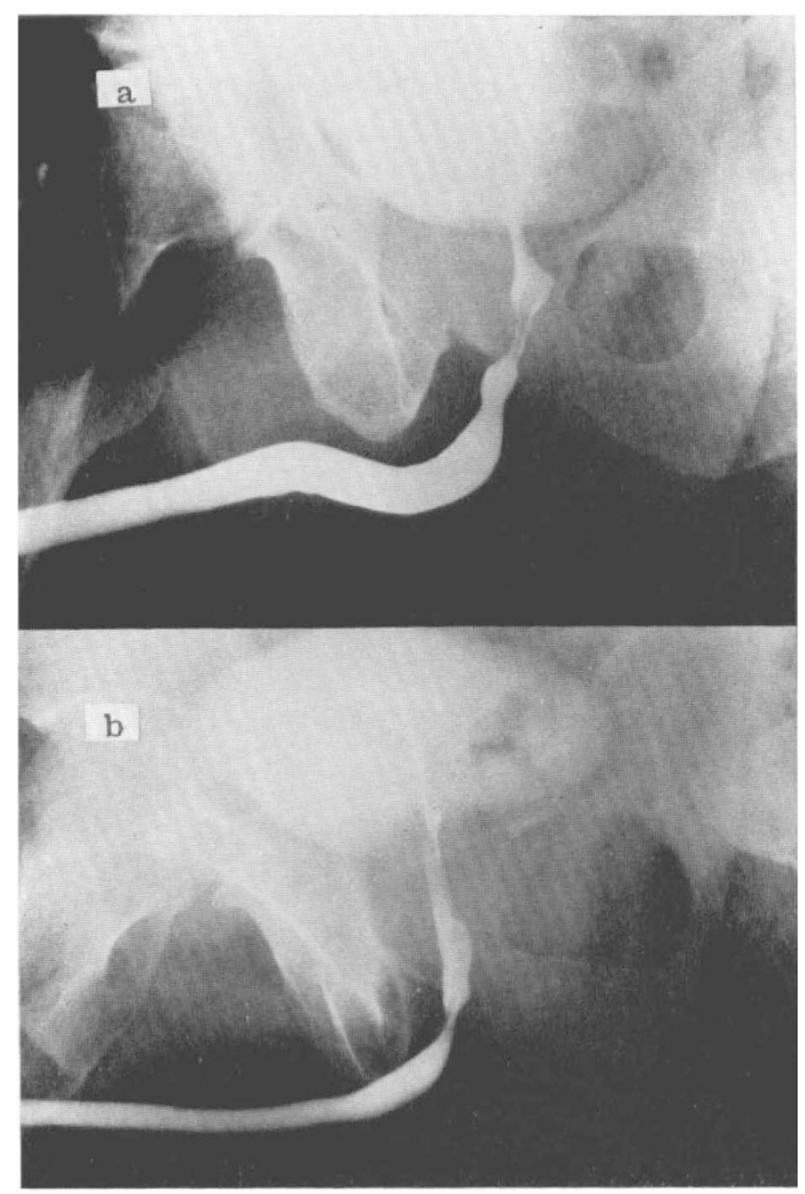

FIG. 7

A. M., 38-year-old paraplegic patient with UMNL. (A) Pre-operative retrograde urethrocystogram. Residual urine $400 \mathrm{ml}$. (B) Urethrocystogram 4 weeks after external sphincterotomy. Residual urine was reduced below $100 \mathrm{ml}$.

\section{SUMMARY}

In our department for paraplegics a total of 554 patients have received treatment during the past $2 \frac{1}{2}$ years. On 65 of these patients-that is 12 per cent. -84 urological operations were performed: Litholapaxy in 13 cases, T.U.R. of the prostate gland in 23 , meatotomy in 7 , plastic surgery on the urethra in 4 , bladder neck resection in female in 12 , in male in 17 , and external sphincterotomy in 8 cases. Techniques and results of these operations are discussed. Litholapaxy is 
indicated for whenever bladder stones are present. T.U.R. of the prostate gland, bladder neck resection and transurethral external sphincterotomy yield good results, when the special indications for these operations are observed.

\section{REFERENCES}

Browne, D. (1949). An operation of hypospadias. Proc. roy. Soc. Med. 42, 446.

CECIL, A. B. (1946). Repair of hypospadias and urethral fistula. f. Urol. (Baltimore), 56, 237.

CeCIL, A. B. (I952). Modern treatment of hypospadias. F. Urol. (Baltimore), 67, Ioo6.

CULP, O. S. \& MCRoBerTs, J. W. (I968). Malformation. Encyclopedia of Urology, VII, I, 306-344. Berlin, Heidelberg, New York: Springer Verlag.

Currie, R. J., Bilbisi, A. A., Schiebler, J. C. \& BuUTS, R. C. (I970). External sphincterotomy in paraplegics. Techniques and results. F.Urol. (Baltimore), ro9, 64.

EMmetT, J. L. (1945). Transurethral resection in treatment of true and pseudocord bladder. F. Urol. (Baltimore), 53, 545 .

EMmETt, J. L. (1947). Further observations in the management of cord bladder by transurethral resection. f. Urol. (Baltimore), 57, 29.

GutTmanN, L. (1947). Discussion on the treatment and prognosis of traumatic paraplegia. Proc. roy. Soc. Med. 40, 219.

GutTMANN, L. (1969). Erfahrungen mit der konservativen Behandlung neurugener Blasenentleerungsstörungen. Neurogene Blasenstörungen: pp. I-IO. Stuttgart: Georg Thieme Verlag.

GuttmanN, L. \& Frankel, H. (1966). The value of intermittent catheterisation in the early management of traumatic paraplegia and tetraplegia. Paraplegia, 4, 63.

JoHANSON, B. (I953). Reconstruction of male urethra in strictures. Application of buried intact epithelium technic. Acta Chir. Scand., suppl. 176, 7.

Micha LowsKi, E. \& MoDELSKI, W. (I963). Operative treatment of hypospadias. F.Urol. (Baltimore), 89, 698.

Ross, J. C., Gibbon, N. O. K. \& Damanski, M. (1958). Division of external urethral sphincter in the treatment of the paraplegic bladder. Brit. F. Urol. 30, 204.

Ross, J. C., GibBon, N. O. K. \& Damanski, M. (1958). Resection of the external sphincter in the paraplegic-preliminary report. F. Urol. (Baltimore), 79, 742.

Ross, J. C., GibBon, N. O. K. \& Damanski, M. (1963). Further experiences with division of the external urethral sphincter in the paraplegic. F. Urol. (Baltimore), 89, 692.

SMYthe, C. A. (1967). Division of the external sphincter in the treatment of the neurogenic bladder. Brit. F. Surg. II, 627.

SMYTHE, C. A. (I966). External sphincterotomy in the management of the neurogenic bladder, a preliminary report. $\mathcal{F}$. Urol. (Baltimore), 96, $3 \mathrm{I}$.

URAT-I-Prospekt-Instruktion. V/O 'Medexpert' Moskau. 